Research Article

\title{
Experimental Investigation of Geosynthetic-Reinforced Pile-Supported Composite Foundations under Cyclic Loading
}

\author{
Kaifu Liu $\left(\mathbb{D},{ }^{1}\right.$ Yiguo Yang $\left(\mathbb{D},{ }^{2}\right.$ Lei Wang $\mathbb{D},{ }^{3}$ Jiapei Xu $\mathbb{D},{ }^{4}$ and Xinyu Xie $\mathbb{D}^{2}$ \\ ${ }^{1}$ School of Civil Engineering and Architecture, Zhejiang Sci-Tech University, Hangzhou 310018, China \\ ${ }^{2}$ Center of Coastal and Urban Geotechnical Engineering, Zhejiang University, Hangzhou 310058, China \\ ${ }^{3}$ Department of Civil Engineering, University of the District of Columbia, Washington, DC 20008, USA \\ ${ }^{4}$ Linhai Water Group Co. Ltd., Linhai 317000, China \\ Correspondence should be addressed to Kaifu Liu; liukaifu@zstu.edu.cn
}

Received 14 September 2020; Revised 19 November 2020; Accepted 4 December 2020; Published 18 December 2020

Academic Editor: Melina Bosco

Copyright (C) 2020 Kaifu Liu et al. This is an open access article distributed under the Creative Commons Attribution License, which permits unrestricted use, distribution, and reproduction in any medium, provided the original work is properly cited.

\begin{abstract}
A series of model tests were conducted in this study to investigate the deformation characteristics of geosynthetic-reinforced pilesupported (GRPS) composite foundations under cyclic loading. The effects of the applied load, the number of geogrid layers, and types of piles on the performance of the GRPS composite foundation were studied through 1g physical models of composite foundation with well-planned instrumentation. Furthermore, a numerical fitting method was used to assess the relationship between the foundation settlement and the number of load cycles. The results show that with the increase in the magnitude of cyclic load and the number of load cycles, the settlement of GRPS composite foundations and the strain of the pile and geogrid increased accordingly. Adding rigid piles and increasing the number of geogrid layers both could reduce the settlement of GRPS composite foundations, while adding rigid piles was more effective. The relationship between the foundation settlement and the number of load cycles can be expressed by an exponential regression function. The pile strain varied from place to place that the strain of the upper part of the pile was greater than that of the lower part. The geogrid showed a significant impact on the load transfer mechanism of the composite foundation as the geogrid closer to piles endured larger strain. It is critical to consider the variation of the pile strain and the geogrid strain under cyclic loading in the geotechnical practice of composite foundation. The model test results also suggest that the use of GRPS system can effectively reduce the composite foundation settlement. This paper can provide useful references for developing the theoretical framework and design guides for GRPS composite foundations under cyclic loading.
\end{abstract}

\section{Introduction}

Soft soils, like mucky clay with poor physical and mechanical properties, are often distributed along coastal areas. The foundations built on soft soils often face challenging safety issues, such as low bearing capacity and intolerable total and differential settlements, which can induce serious engineering accidents. Compared with conventional composite foundations, a geosynthetic-reinforced pile-supported (GRPS) composite foundation can improve the bearing capacity and has been widely employed in many civil infrastructure projects such as high-speed railways in China [1-3].
The usage of rigid and flexible piles in composite foundations can effectively reduce total settlements and improve their bearing capacity $[4,5]$. The differential settlement between the piles and the soil can develop soil arch in the soil, which has a great influence on load transfer and deformation characteristics [6-9]. Liu et al. [2] reported that there was significant load transfer from the soil to the piles in a GRPS embankment that the measured contact pressure acting on the pile was about 14 times higher than that acting on the soil located between the piles. Also, Chen et al. [1] conducted three field tests and concluded that there was significant soil arching in the pile-supported embankment and the measured earth pressures acting on the piles are 
much higher than those acting on the soils between the piles. Han and Gabr [10] conducted a numerical analysis and reported that the maximum tension in the geosynthetic reinforcement of a GRPS foundation occurred near the edge of the pile.

In addition, the application of the geosynthetic reinforcement in the composite foundation can effectively improve the performance of the foundation $[3,8,11]$. It has been reported that the geogrid reinforcement is used to transfer load to the piles through membrane effects $[12,13]$ and the inclusion of geogrid reinforcement can also reduce the total and differential settlements between the piles and the soil between the piles [11-14]. Several studies about the effects of the geogrid reinforcement on the composite foundation under different conditions have been reported. Compared with foundations without geogrid reinforcement, the GRPS composite foundation with geogrid reinforcement is proved to have an improved performance of less settlement and more stability [8, 15-18]. Additionally, increasing the tensile stiffness of the geogrid and the number of geogrid layers have positive effects on the load transfer $[10,19,20]$. When the composition has more than one layer of geogrid reinforcement, Ye et al. [9] concluded that the lower layer had a significant effect on load transfer than the other layers. Also, Shen et al. [21] pointed out that compared with increasing the tensile stiffness of the geogrid, decreasing reinforcement vertical spacing could significantly increase the global elastic modulus of the composite foundation and reduce the lateral facing displacements.

The traffic load can be simulated as a cyclic load, and it has been shown that several problems will occur on the foundation built on soft clay under cyclic loading [16, 17]. Higher strains in the geogrid, soil arching reduction, larger stress, and larger settlement were identified in a GRPS embankment under sinusoidal cyclic loading [11]. A number of experimental and numerical studies on the composite foundations subjected to cyclic loading have been conducted. Alam et al. [22] conducted a series of large-scale model tests to investigate the accumulation of permanent footing displacement and residual vertical soil stress over a large number of load cycles. Wang and Chen [23] presented an estimating method to calculate the static and dynamic stresses in the GRPS track bed, based on a series of full-scale model tests under train moving loads. Han et al. [24] investigated the stress distribution and stability of an embankment of various heights under cyclic loading, and the minimum height of an embankment was reported to ensure the stability of the model. Pham and Dias [25] conducted numerical modeling and studied the influence of the number of traffic load cycles, the vehicle speed, and the embankment height on the arching effect and cumulative settlements. Wang et al. [26] evaluated the variation of soil stress, the evolution of soil arching, and the load transfer mechanism of GRPS track bed at various water levels and loading cycles.

However, previous studies only deal with the GRPS composite foundation with the same type of piles under static or cyclic loading. In this study, physical models of the GRPS composite foundation were established, with rigidflexible piles and various layers of geogrid reinforcement. A set of cyclic loads were applied on the composite foundation to simulate the traffic load. This experimental study evaluated the effects of various factors, including the type of piles, the number of geogrid layers, the number of load cycles, and the magnitude of cyclic load on the deformation characteristics of the composite foundation.

\section{Materials and Methods}

2.1. Equipment for Model Tests. The testing equipment is presented in Figure 1, which comprised a model tank, a loading plate, and a counter-force apparatus system. The model tank, measuring $1500 \mathrm{~mm}$ (length) $\times 900 \mathrm{~mm}$ (width) $\times 1700 \mathrm{~mm}$ (height), was made of welded steel, while the steel plate on one side was replaced with a piece of tempered glass to facilitate the filling of soil and observe the changes of soil. The side walls of the model tank were stiffened with steel tubes to ensure that no lateral deformations occurred due to earth pressure induced by the application of loading. The counter-force apparatus system adopted an electro servo loading system and an actuator to record and collect vertical displacements in real time during the loading process with displacement sensors. The strain data were automatically collected by the data acquisition system. The loading plate was a steel plate measuring $1300 \mathrm{~mm}$ (length) $\times 800 \mathrm{~mm}$ (width) $\times 20 \mathrm{~mm}$ (height). The distribution of vertical displacement over the base plane of this plate was the same because of the steel plate stiffness. The vertical displacement of the plate was recorded as composite foundation settlement. The vertical load at the top of the respective piles could be obtained by the measured pile strain.

2.2. Materials for Tests. To simulate the situation of a real soft soil foundation, the test soil (silty clay and mucky clay) was taken from a foundation pit in Hangzhou, China. The model foundation was formed by the aforementioned remolded soil under stratified filling. The physical and mechanical properties of the soil are shown in Table 1. The strength parameters of silty soil and mucky soil were obtained by the direct shear test of quick shear methods. The cushion used fine sand as the material with a fineness modulus of 1.6 and a moisture content of $4 \%$. Before the test, the initial moisture content of the soil was determined according to the ASTM soil test method as the reference water content. The silty clay used in the model test was classified as MH-elastic silt, and the mucky clay was classified as CL-lean clay [27]. The soil was then reprepared before filling to reach the reference moisture content. The soil was filled in equal weight and equal volume ( $50 \mathrm{~mm}$ per layer) during the process of filling. To control the compaction of the soil, the soil was preloaded under the same weight in the same time period in the model test.

The rigid pile used an $800 \mathrm{~mm}$-long steel pipe (penetrating through the mucky clay layer) with outer and inner diameters of $50 \mathrm{~mm}$ and $46 \mathrm{~mm}$, respectively. The rigid pile was welded with a steel block $(100 \mathrm{~mm} \times 100 \mathrm{~mm} \times 20 \mathrm{~mm})$ as the pile cap. The flexible pile used a $600 \mathrm{~mm}$-long PVC 


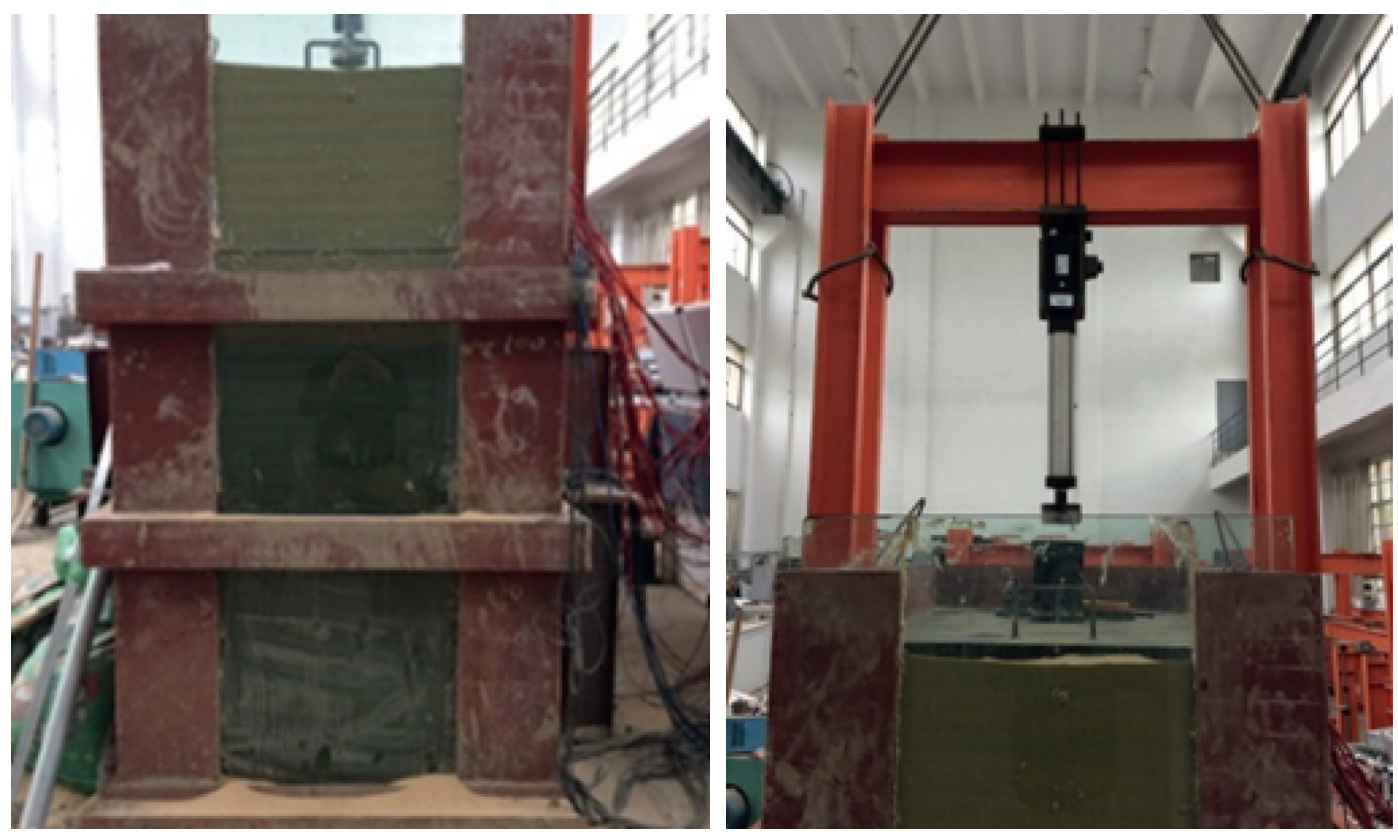

FIGURE 1: Test equipment used in the model test.

TABle 1: Physical and mechanical properties of silty and mucky soil.

\begin{tabular}{lccccc}
\hline Soil type & Moisture content, $(\%)$ & Density, $\left(\mathrm{g} / \mathrm{cm}^{3}\right)$ & Cohesion, $(\mathrm{kPa})$ & Internal angle of friction, $\left({ }^{\circ}\right)$ & Compression modulus, $(\mathrm{MPa})$ \\
\hline Silty soil & 19.4 & 1.80 & 10.9 & 28.4 & 8.24 \\
Mucky soil & 34.0 & 1.70 & 12.3 & 10.9 & 3.48 \\
\hline
\end{tabular}

pipe (not penetrating through the mucky clay layer) with outer and inner diameters of $50 \mathrm{~mm}$ and $46 \mathrm{~mm}$, respectively. In addition, two round steel sheets were installed at each end of the PVC pipe to prevent soil particles from entering into the pipe.

The geogrid adopted biaxially stretched plastic geogrids. The geogrid had a gird size of $30 \mathrm{~mm} \times 30 \mathrm{~mm}$ and the tensile strength of $30 \mathrm{kN} / \mathrm{m}$ in both longitudinal direction and transverse direction. Each layer of the geogrid-reinforced cushion with fine sand had a thickness of $50 \mathrm{~mm}$.

2.3. Experimental Design. Figures 2 and 3 are the vertical and the horizontal layouts of the model test on the composite foundation with rigid-flexible piles, respectively. If the rigid piles in Figure 2 were removed, the composite foundation became a composite foundation with flexible piles. The strain gauges, which were attached to the inner side of piles to reduce strain gauges' influence on the pile side friction resistance and pile strain, adopted uniaxial resistance strain gauges and had a resistance of $120 \Omega$. Considering the symmetry, the strain of one flexible corner pile and one flexible side pile were measured. The layout of the strain gauges on flexible piles is shown in Figure 2.

After the foundation filling was completed in the model tank, piles were pressed into the foundation manually following the static press construction method used in the engineering practice after partial boring on the pile position. The top of piles was leveled with the top surface of the upper silty clay layer. The geogrid and the fine sand were placed above the upper silty clay layer as a reinforced cushion. The geogrid was anchored around with an anchor length of $100 \mathrm{~mm}$ (Figure 2). The detailed arrangement of strain gauges on the geogrid is shown in Figure 4. Additionally, to improve the accuracy of data acquisition and adapt to the size of geogrid, the width of the strain gauges used in the model test was $2 \mathrm{~mm}$.

Traffic load is an instantaneous load related to factors such as the vehicle structure, road performance, and driving speed. This study used a simple sinusoidal cyclic load proposed by Chen [28], which can reflect cycle characteristics, driving speed effects, and geometric irregularities to simulate the traffic load. The dynamic expression is

$$
\begin{aligned}
F(t) & =P_{a}+P_{b} \sin (\omega t), \\
\omega & =\frac{2 \pi v}{l},
\end{aligned}
$$

where $P_{a}$ is the wheel load, $P_{b}$ is the amplitude, $\omega$ is the vibration frequency, $v$ is the driving speed, and $l$ is the vehicle length. Considering the typical vehicle length of $3.6-5.5 \mathrm{~m}$ and the driving speed of $20-100 \mathrm{~km} / \mathrm{h}$, the corresponding vibration frequency is about $1-5 \mathrm{~Hz}$. Hence, the cyclic load with a frequency of $1 \mathrm{~Hz}$ is used to simulate the traffic load in this model test.

To compare and analyze the settlement, pile strain, and geogrid strain of the composite foundation under static loading and cyclic loading, a number of model tests (as 


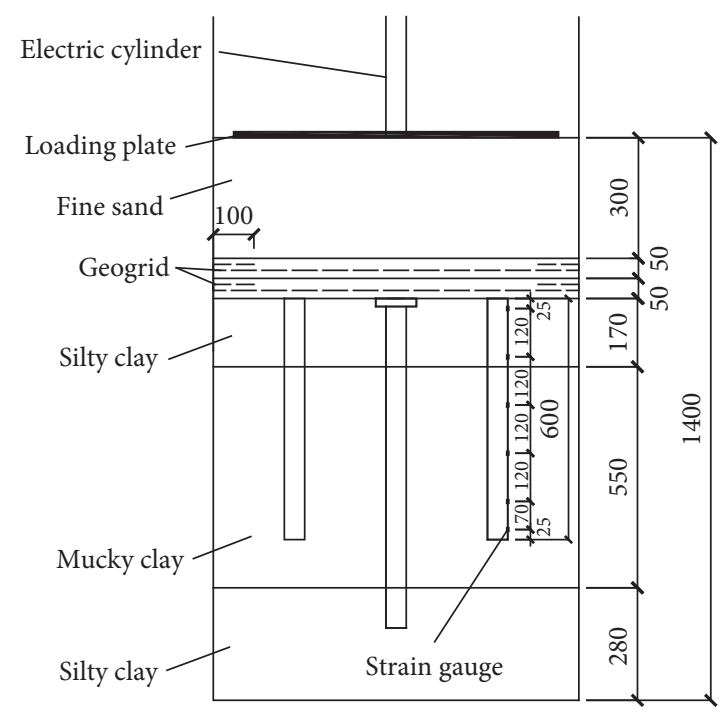

Figure 2: Vertical layout of the model test (unit: mm).

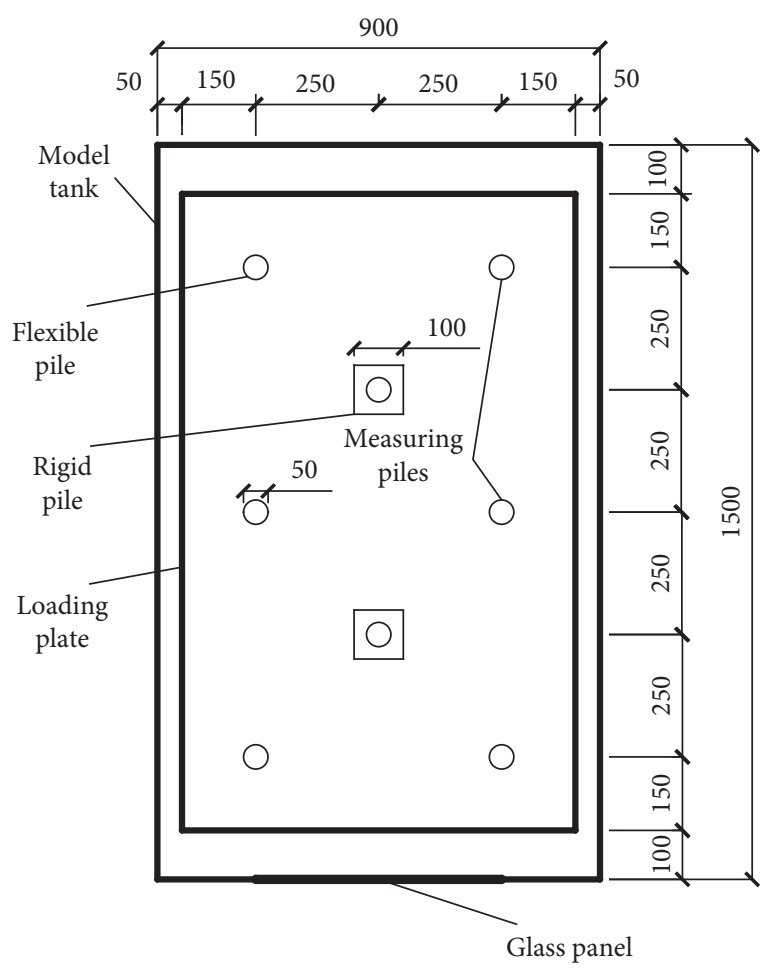

FIgURE 3: Horizontal layout of the model test (unit: $\mathrm{mm}$ ).

shown in Table 2) were designed. For the sake of simplicity, "FG1" represents model tests on composite foundations with flexible piles and one layer of the geogrid, "RFG1" represents model tests on composite foundations with rigid-flexible piles and one layer of the geogrid, and "RFG2" represents model tests on composite foundations with rigid-flexible piles and two layers of the geogrid.

Figure 5 depicts the static load loading diagram and the cyclic load loading diagram. The static load was applied in stages, and 0.5 kN was applied per stage (shown in Figure 5(a)). After each stage of load was applied and the data were stabilized

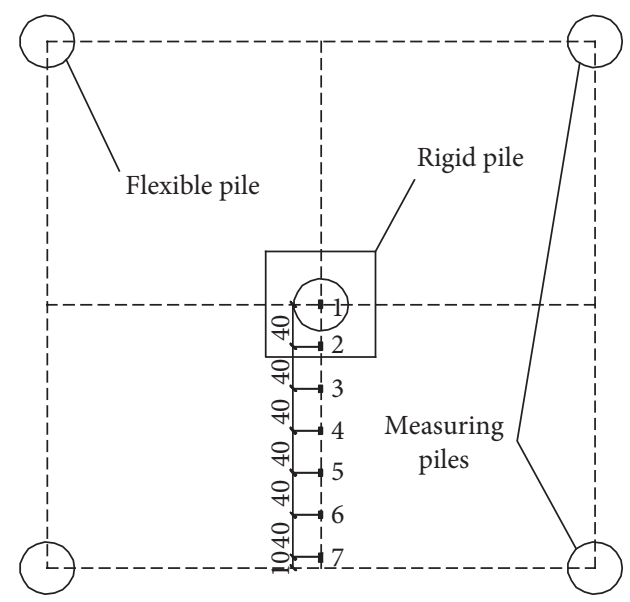

FIGURE 4: Layout of strain gauges on the geogrid (mm).

(the increment of settlement was less than $0.01 \mathrm{~mm}$ and the strain change was less than $1 \mu \varepsilon$ in $30 \mathrm{~min}$ ), the next stage of load would be applied. After being applied to $5 \mathrm{kN}$, the applied load was unloaded to 0 at $1.0 \mathrm{kN}$ per stage. The cyclic load was applied after 12 hours of static load unloading. The load would be increased linearly to $3 \mathrm{kN}$ (the median value of the cyclic load) at a rate of $0.3 \mathrm{kN} / \mathrm{min}$, and then the cyclic load would be applied (shown in Figure 5(b)). The cyclic load application sequence was to apply a sinusoidal cyclic load with a magnitude of $3 \pm 1 \mathrm{kN}$ with the cycles of 50,000, and then the magnitude was increased to $3 \pm 2 \mathrm{kN}$ for another 50,000 cycles, with the frequency of $1 \mathrm{~Hz}$. Between the two cyclic loads, the load was held for 12 hours at $3 \mathrm{kN}$. The cyclic load interval between the two groups was 12 hours.

\section{Results and Discussion}

3.1. Composite Foundation Settlement. Figure 6 shows the load-settlement curves of three GRPS composite foundations under static load. As seen in Figure 6, the settlements of 
TABLE 2: Configuration of the model tests.

\begin{tabular}{lcc}
\hline Test No & Name & Loading procedure \\
\hline 1 & FG1 & Static load, cyclic load $3 \pm 1 \mathrm{kN}$, cyclic load $3 \pm 2 \mathrm{kN}$ \\
2 & RFG1 & Static load, cyclic load $3 \pm 1 \mathrm{kN}$, cyclic load $3 \pm 2 \mathrm{kN}$ \\
3 & RFG2 & Static load, cyclic load $3 \pm 1 \mathrm{kN}$, cyclic load $3 \pm 2 \mathrm{kN}$ \\
\hline
\end{tabular}

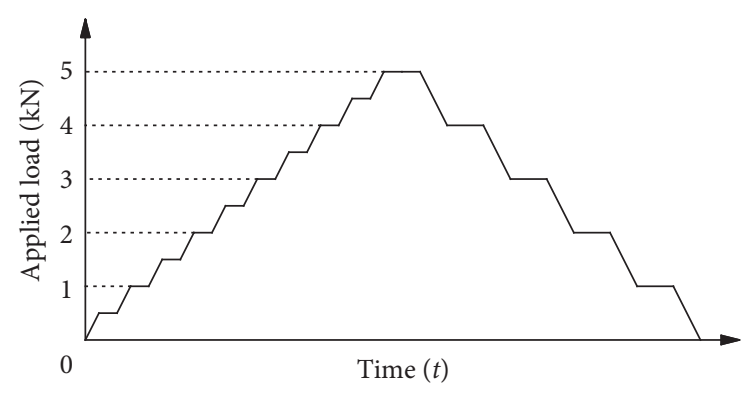

(a)

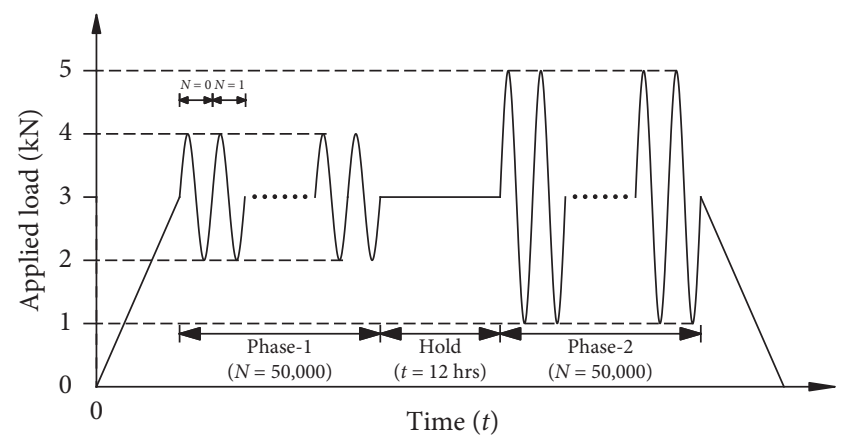

(b)

Figure 5: Applied load in the model test: (a) static load and (b) cyclic load.

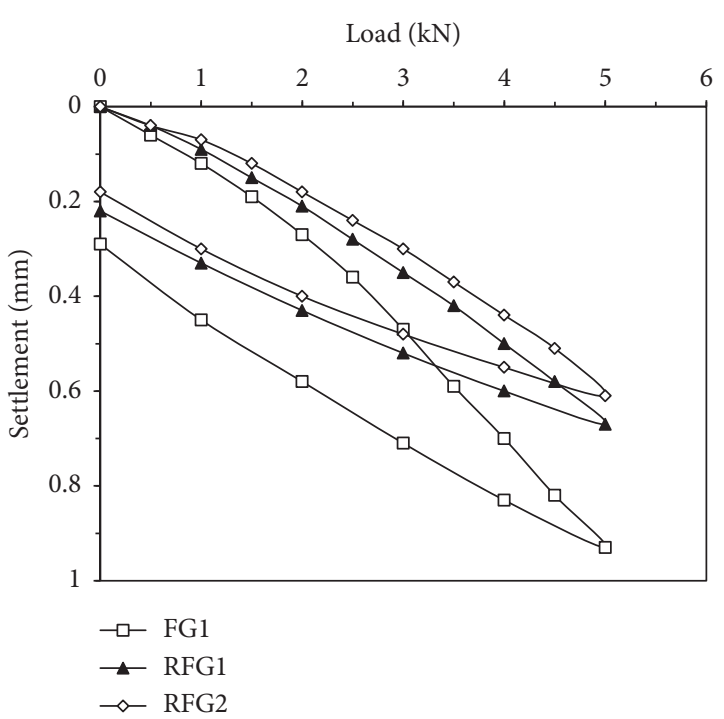

FIGURE 6: Load-settlement curves of GRPS composite foundations under static loads.

all the composite foundations increased when the static load was applied stage by stage. When the static load reached $5 \mathrm{kN}$, the settlement of RFG1 was $0.67 \mathrm{~mm}$, which was $28.0 \%$ lower than that of FG1. This indicated that the addition of rigid piles had an evident effect to reduce the settlement of the composite foundation. It is found that more layers of reinforcements can increase the stiffness of the foundation soils, which is consistent with the conclusions by Wang et al. [29]. The settlement of RFG2 was $11.9 \%$ lower than that of RFG1, which showed that increasing the number of geogrid layers could also reduce the settlement of the composite foundation to a certain extent. Compared with geogrids, piles played a more important role on reducing the total settlement. In other words, the addition of piles has a greater influence on settlement reduction than the addition of geogrid layers.

Figure 7 shows the settlement-number of load cycles curves of GRPS composite foundations under cyclic load. It is noticeable that the settlements of composite foundations increased and the increasing rate of settlements gradually decreased with the increasing number of load cycles. For example, under the cyclic load $3 \pm 1 \mathrm{kN}$, the settlement of RFG2 after 5,000 load cycles was $0.73 \mathrm{~mm}$, which was $0.18 \mathrm{~mm}$ larger than the initial settlement of $0.55 \mathrm{~mm}$ (the settlement under a static load of $5 \mathrm{kN}$ ). However, after 10,000 load cycles, the settlement only increased by $0.03 \mathrm{~mm}$; evidently, the cumulative settlements of composite foundations under cyclic load developed fast in the first 5,000 cycles and gradually became stable in the later period. The results are consistent with the findings by Alam et al. [22]. However, Alam et al. [22] concluded that permanent displacement accumulated asymptotically with load cycles and the majority of the build-up occurred over the first few hundred cycles, while the settlement became stable after 10,000 cycles in this study, and this may be caused by differences in soil properties. The soil used in Alam's study was compacted sand, which evidently had smaller residual deformation than the soft soil used in this study.

When the number of load cycles was 50,000 and the magnitude of cyclic load changed from $3 \pm 1 \mathrm{kN}$ to $3 \pm 2 \mathrm{kN}$, the curves suddenly dropped and the increasing rate of the settlement increased significantly. When the number of load cycles increased from 50,000 to 55,000, the cumulative settlement of RFG2 increased from $1.05 \mathrm{~mm}$ to $1.48 \mathrm{~mm}$ and the increment was $0.43 \mathrm{~mm}$, which was similar to the total settlement developed under the load of previous 50,000 load cycles. In addition, the settlement developed under the load of later 50,000 load cycles was almost twice as large as that 


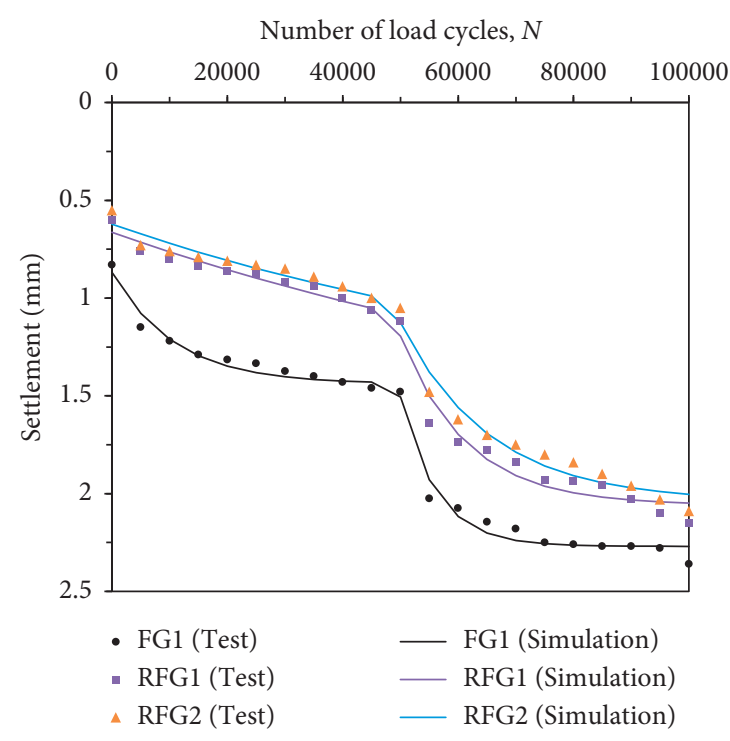

FIGURE 7: Settlement-number of load cycles curves of GRPS composite foundations under cyclic loads.

developed under the load of previous 50,000 load cycles. This means that the increase of cyclic load magnitude will result in a larger settlement.

When the number of load cycles was 100,000 , the final settlement of RFG1 was $2.15 \mathrm{~mm}$, which was $0.21 \mathrm{~mm}(8.9 \%)$ smaller than that of FG1 $(2.36 \mathrm{~mm})$, and the settlement of RFG2 was $2.09 \mathrm{~mm}$, which was $0.06 \mathrm{~mm}(2.8 \%)$ smaller than that of RFG1. This showed a similar characteristic as that under static load. However, when the number of load cycles increased from 0 to 100,000, the increments of settlements of FG1, RFG1, and RFG2 were $1.53 \mathrm{~mm}, 1.55 \mathrm{~mm}$, and $1.54 \mathrm{~mm}$, respectively. Although the addition of rigid piles and geogrid layers could reduce the final settlement, the total settlement increments of these composite foundations were almost equal under cyclic loading with 100,000 load cycles. It can be seen from Figure 7 that the increasing rates of the settlement of RFG1 and RFG2 were slightly larger than that of FG1. It can be predicted that these three curves would converge closer when cyclic loads with much more load cycles were applied.

In order to further study the relationship between the composite foundation settlement $S$ and the number of load cycles $N$, the magnitude of cyclic load, the addition of rigid piles, the number of geogrid layers, and the numerical fitting of the foundation settlement-number of load cycles curves (as shown in Figure 7) were evaluated using regression analyses. The relationship can be expressed by

$$
S=\alpha e^{\beta N}+C,
$$

where $\alpha$ and $\beta$ are the fitting values, $C$ is the constant term, and $R^{2}$ is the determination coefficient. The resulting values of $\alpha, \beta, C$, and $\mathrm{R}^{2}$ are given in Table 3. The $R^{2}$ values indicate that the exponential regression models generally fit well with the measured data. It can be seen from Table 3 that compared with the GRPS composite foundation with flexible piles, the values of $\beta$ of the GRPS composite foundation with rigid-flexible piles are much smaller, which means the addition of rigid piles can significantly reduce the foundation settlement. Increasing the magnitude of cyclic load can lead to the corresponding increase of the values of $\beta$, which proves that the change in magnitude can result in the change in composite foundation settlement in an exponential manner.

3.2. Pile Strain. The pile strain reflects the axial force of the pile and the development of side friction resistance. The difference in the strain of different piles reflects the stress distribution of each pile. Considering the limitations of the length, this study only discusses the strain of flexible piles in RFG1 under cyclic loading with a magnitude of $3 \pm 2 \mathrm{kN}$.

Figure 8 shows the pile strain-buried depth curves of side piles with different numbers of load cycles under cyclic loading. It can be seen from Figure 8 that with the increase in the number of load cycles, the pile strain increased [11] and the increment of the strain gradually decreased. When the number of load cycles was 10,000, the increment of pile strain near the pile top (buried depth $25 \mathrm{~mm}$ ) was $10.54 \mu \varepsilon$, which was $23.02 \%$ larger than the scenario of 0 cycle (static load of $5 \mathrm{kN}$ ). When the number of load cycles increased to 30,000 , the pile strain increment was $5.04 \mu \varepsilon$, which increased by $8.95 \%$, and when the number of load cycles increased to 50,000 , the increment was $3.27 \mu \varepsilon$, which increased by $5.33 \%$.

Also, when the number of load cycles increased, the increment of the pile strain increased with the increase of buried depth until the buried depth reached $145 \mathrm{~mm}$ and then decreased with the increase of buried depth. For example, when the number of load cycles increased from 0 to 10,000 , the increments of the pile strain at buried depths of $25 \mathrm{~mm}, 145 \mathrm{~mm}, 265 \mathrm{~mm}, 385 \mathrm{~mm}, 505 \mathrm{~mm}$, and $575 \mathrm{~mm}$ were $10.53 \mu \varepsilon, 13.91 \mu \varepsilon, 11.50 \mu \varepsilon, 10.22 \mu \varepsilon, 6.21 \mu \varepsilon$, and $8.57 \mu \varepsilon$, respectively. When the number of load cycles increased to 20,000, the increments became $2.39 \mu \varepsilon, 4.83 \mu \varepsilon$, $4.80 \mu \varepsilon, 4.66 \mu \varepsilon, 1.47 \mu \varepsilon$, and $2.33 \mu \varepsilon$, respectively. Compared 
TABLE 3: Fitting values of $\alpha, \beta$, constant $C$, and coefficient of determination $R^{2}$.

\begin{tabular}{|c|c|c|c|c|}
\hline Test & $\alpha$ & $\beta$ & $C$ & $R^{2}$ \\
\hline $\mathrm{FG} 1,3 \pm 1 \mathrm{kN}$ & -0.5719 & -0.9216 & 1.439 & 0.9587 \\
\hline $\mathrm{FG} 1,3 \pm 2 \mathrm{kN}$ & -0.764 & -1.614 & 2.27 & 0.9539 \\
\hline RFG1, $3 \pm 1 \mathrm{kN}$ & -1.183 & -0.08884 & 1.846 & 0.9431 \\
\hline $\mathrm{RFG} 1,3 \pm 2 \mathrm{kN}$ & -0.8646 & -0.8709 & 2.06 & 0.9318 \\
\hline RFG2, $3 \pm 1 \mathrm{kN}$ & -0.9344 & -0.1108 & 1.556 & 0.9217 \\
\hline $\mathrm{RFG} 2,3 \pm 2 \mathrm{kN}$ & -0.9134 & -0.6477 & 2.039 & 0.9527 \\
\hline
\end{tabular}

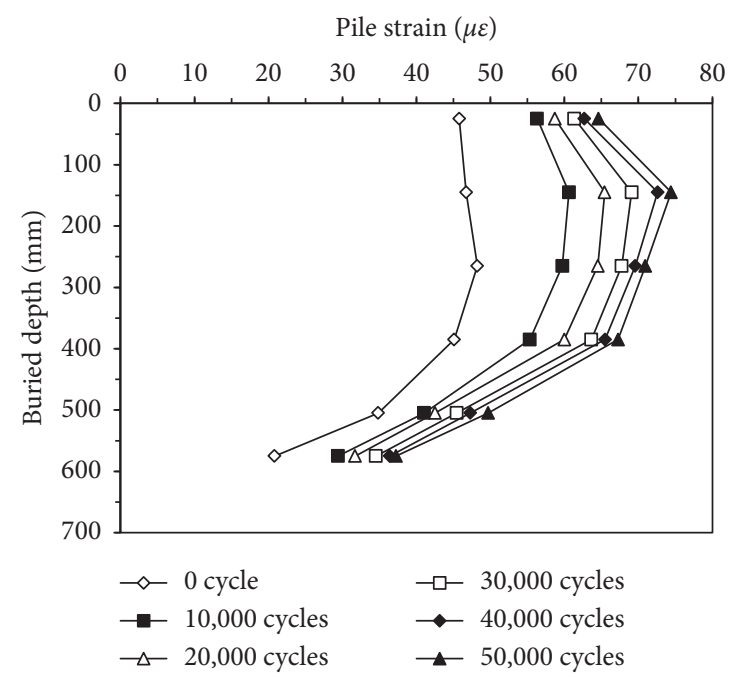

FIGURE 8: Pile strain-buried depth curves of side piles with different numbers of load cycles under cyclic loading.

with the pile strain near the top of the pile, the pile strain near the bottom of the pile was only slightly affected by the number of load cycles. This may be because the pile-soil interface was subjected to repeated shearing effect [30], and the cyclic load caused the soil arching $[9,18,26]$ to be rearranged and a certain amount of plastic deformation remained, which caused the increment of pile side friction resistance and eventually lead to an increase in pile strain. At the initial stage of cyclic loading, the repeated shearing effect [30] was obvious and the increment of pile strain was largely relatively. With the increase of the number of load cycles, the repeated shearing effect was weakened and the corresponding pile strain increment decreased.

Additionally, while the number of load cycles increased, the pile strain at a depth of $25 \mathrm{~mm}$ had a smaller growth than that at a depth of $145 \mathrm{~mm}$, which was caused by the negative friction on the pile side [18]. When the number of load cycles increased to a relatively larger value, the settlement of the soil accumulated and the soil could have larger compressions than the piles, which would cause the soil to move downward relative to the piles and to exert an upward force on the piles. Thus, the upper part of the pile would have smaller strain than the lower part of the pile.

Figure 9 depicts the pile strain-buried depth curves of the corner pile and the side pile under cyclic loading when the magnitude is $3 \pm 2 \mathrm{kN}$ and the number of load cycles is 50,000 . As shown in Figure 9, the strain of the corner pile was larger than that of the side pile, which indicated that the corner pile was subjected to a larger load than the side pile. For example, at a buried depth of $145 \mathrm{~mm}$, when the cyclic load was at its peak $(5 \mathrm{kN})$, the strain of the corner pile was $90.63 \mu \varepsilon$, which was $21.78 \%$ larger than that of the side pile $(74.42 \mu \varepsilon)$. In addition, when the cyclic load increased from the valley value to the peak value, the strain of the corner pile had more increment than that of the side pile. This was because the loading plate was a rigid plate and was difficult to bend under external load, which would result in the contact pressure transferred from the center of the foundation to the edges.

3.3. Geogrid Strain. Figure 10 shows the geogrid strain distribution curves of the geogrid in RFG1 under static load (taken the top position of the rigid pile as the origin, as shown in Figure 4). It can be seen from Figure 10 that the geogrid strain increased with the increase of the load. Also, the geogrid strain was larger when the geogrid was closer to the rigid pile, and the geogrid strain at the junction between the piles and the soil between piles was the largest, which is consistent with the result concluded by Han and Gabr [10] and Liu et al. [14]. This may be because that the tensile effect generated by the geogrid $[13,31]$ caused the stress of the soil between piles to shift to the pile top so that the normal stress on the geogrid at the pile top was greater than that between the piles. According to Mohr-Coulomb theory, the shear strength of soil is linear with the normal stress. Therefore, the larger the normal stress was, the larger the shear stress on the geogrid would be. This caused the geogrid subjected to greater tensile stress and to have more strain. 


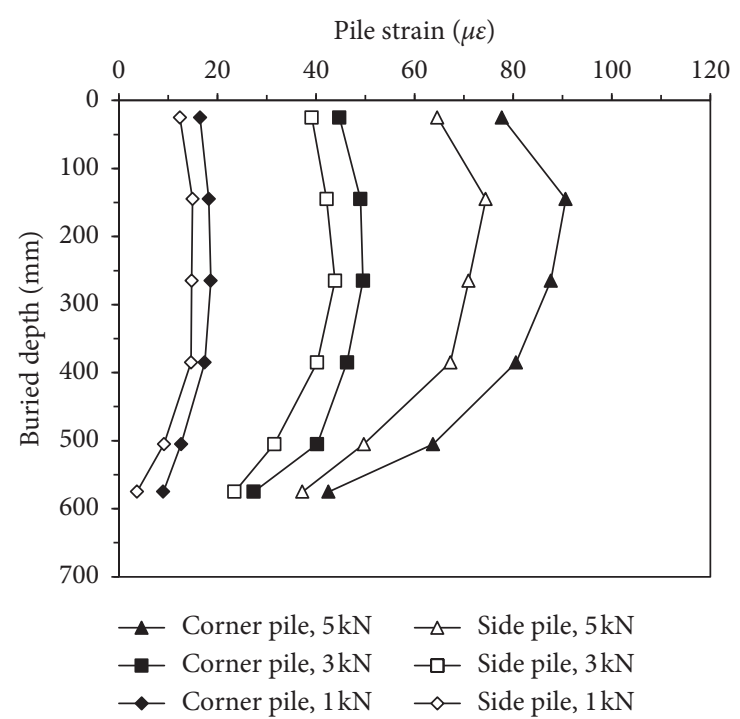

Figure 9: Pile strain-buried depth curves of corner pile and side pile with the number of load cycles of 50,000 under cyclic loading.

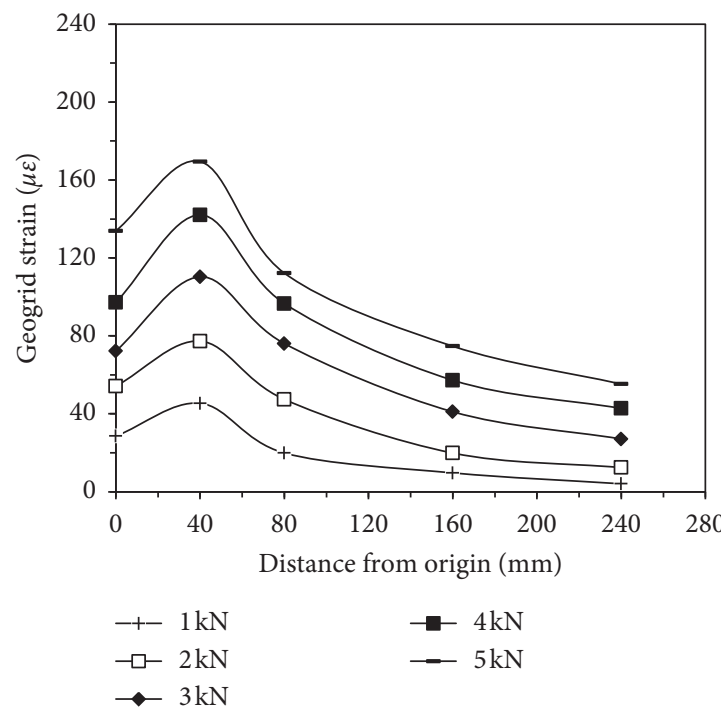

FIGURE 10: Geogrid strain distribution curves of the geogrid in RGF1 under static loads.

Figure 11 shows the geogrid strain distribution curves of the geogrid in RGF1 under cyclic loading (with the rigid pile top position as the origin, as shown in Figure 4). In Figure 11, the geogrid strain at the junction between the piles and the soil between piles was the largest, which is consistent with the result under static load $[10,14]$. With the increase in the number of load cycles, the geogrid strain increased while the increment of geogrid strain decreased gradually. Taking the measuring point of No. $1(0 \mathrm{~mm}$ from the origin, as shown in Figure 4) as an example, the geogrid strain was $193.5 \mu \varepsilon$ at 10,000 cycles, which was $59.62 \mu \varepsilon$ or $44.53 \%$ larger than that at 0 cycle $(133.88 \mu \varepsilon)$. Also, the geogrid strain at this point was $231.63 \mu \varepsilon$ at 30,000 cycles $(38.13 \mu \varepsilon$ or $19.70 \%$ larger than that at 10,000 cycles) and increased to $252.58 \mu \varepsilon$ at 50,000 cycles $(20.95 \mu \varepsilon$ or $9.04 \%$ larger than that at 30,000 cycles). With the increase in the number of load cycles, the geogrid strain gradually stabilized and was only slightly influenced by the number of load cycles.

However, it could also be seen from Figure 12 that the geogrid strain of No. 2 measuring point $(40 \mathrm{~mm}$ from the origin, as shown in Figure 4) still had a relatively larger increment than that of other measuring points with the increase of the number of load cycles. When the number of load cycles increased from 0 to 50,000, the increments of the geogrid strain were $69.91 \mu \varepsilon, 43.15 \mu \varepsilon, 32.8 \mu \varepsilon$, and $32.57 \mu \varepsilon$, respectively. According to the membrane effects of the geogrid $[13,31]$, it can be inferred that the No. 2 measuring point, which was located near the rigid pile cap, would bear larger load than other points to transfer load to the piles. Thus, with the increase in the number of load cycles, the geogrid near the rigid pile cap had a relatively larger strain to transfer load, while the geogrid strain of other points 


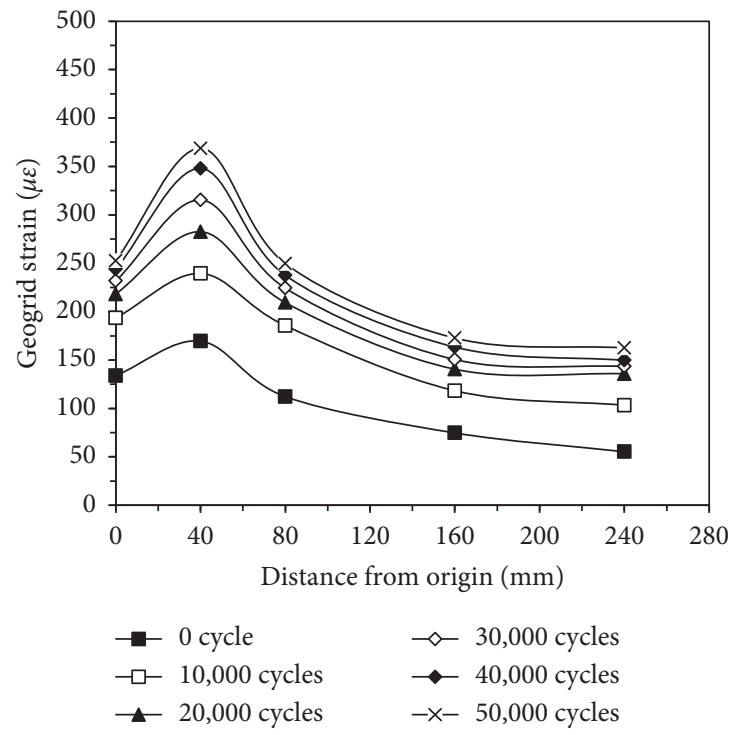

FIGURE 11: Geogrid strain distribution curves of the geogrid in RGF1 under cyclic loading.

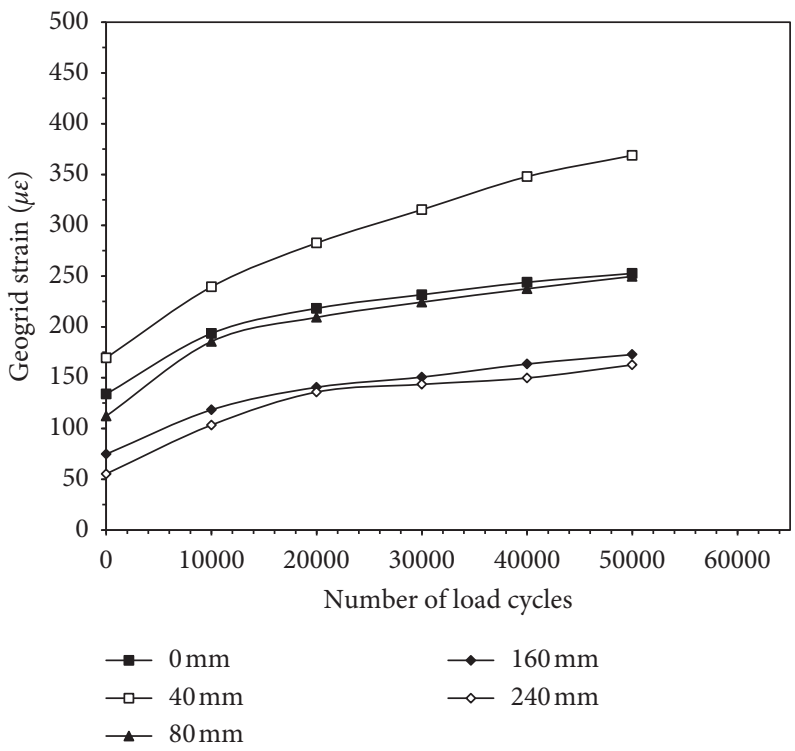

FIGURE 12: Geogrid strain-number of load cycles curves of the geogrid in RGF1 under cyclic loading.

gradually stabilized. It can be also seen from Figure 12 that the geogrid strain gradually stabilized and was only slightly influenced by the number of load cycles with the increase of the number of load cycles.

\section{Conclusions}

Three model tests were conducted in this study to investigate the deformation characteristics of GRPS composite foundations under cyclic loading. It is found in this paper that adding rigid piles and increasing the number of geogrid layers could reduce the settlements of composite foundations, while adding rigid piles could reduce the settlement more effectively. The cumulative settlements of composite foundations under cyclic loading mainly developed in the first 5,000 load cycles and increased slowly in the later period. The magnitude of cyclic load could greatly influence the settlements of composite foundations. When the magnitude increased from $3 \pm 1 \mathrm{kN}$ to $3 \pm 2 \mathrm{kN}$, the settlement of RFG2 increased $41.0 \%$. When the number of load cycles was large enough, the addition of rigid piles and geogrid layers would have little influence on the final settlements. The relationship between the settlement and the number of load cycles can be expressed by an exponential function.

The increase of the number of load cycles can lead to the increasing of pile strain, while the increment of the strain gradually decreased. When the number of load cycles was 10,000 , the increment of pile strain near the pile top was $10.54 \mu \varepsilon$, which was $23.02 \%$ larger than the scenario of 0 cycle. When the number of load cycles increased to 30,000 , 
the pile strain increment increased by $8.95 \%$, and the increment increased by $5.33 \%$ when the number of load cycles increased to 50,000. The number of load cycles evidently influenced the strain of the upper part of piles than that of the lower part of piles. The rigid loading plate used in the model tests would transfer load from the center part to the side part, which would lead to side piles showing greater strain than corner piles under cyclic loading. Cyclic loading had an evident effect on the geogrid strain, which increased with the increase in the number of load cycles, and the geogrid strain developed more significantly in the first 10,000 cycles. The geogrid strain in the composite foundation increased with the increase of the applied load and the number of load cycles. The geogrid strain was larger when the geogrid was closer to the rigid pile, and the geogrid strain at the junction between the piles and the soil is the largest. The results provide experimental basis for mitigating foundation settlements with a GRPS system in geotechnical engineering practice.

\section{Data Availability}

The data used to support the findings of this study are included within the article.

\section{Disclosure}

The results and opinions expressed in this paper do not necessarily reflect the views and policies of both the National Natural Science Foundation of China and the Natural Science Foundation of Zhejiang Province.

\section{Conflicts of Interest}

The authors declare that they have no conflicts of interest.

\section{Acknowledgments}

This work was supported by the National Natural Science Foundation of China (Grant nos. 51878619 and 52078465) and the Natural Science Foundation of Zhejiang Province, China (Grant no. LY13E090010).

\section{References}

[1] R. P. Chen, Z. Z. Xu, Y. M. Chen, D. S. Ling, and B. Zhu, "Field tests on pile-supported embankments over soft ground," Journal of Geotechnical and Geoenvironmental Engineering, vol. 136 , no. 6 , pp. 777-785, 2010.

[2] H. L. Liu, C. W. W. Ng, and K. Fei, "Performance of a geogridreinforced and pile-supported highway embankment over soft clay: case study," Journal of Geotechnical and Geoenvironmental Engineering, vol. 133, no. 12, pp. 1483-1493, 2007.

[3] H.-L. Wang, R.-P. Chen, Q.-W. Liu, and X. Kang, "Investigation on geogrid reinforcement and pile efficacy in geosynthetic-reinforced pile-supported track-bed," Geotextiles and Geomembranes, vol. 47, no. 6, pp. 755-766, $2019 \mathrm{~b}$.

[4] K. Liu, X. Xie, and H. Liu, "Performance of rigid-flexible-pile foundation with cushion," in Proceedings of the Institution of
Civil Engineers-Geotechnical Engineering, vol. 163, no. 4, pp. 221-227, 2010.

[5] X. Xie, X. R. Yang, S. W. Shi, and X. R. Zhu, "Engineering characteristics of composite foundation with rigid-flexible and long-short piles," Rock and Soil Mechanics, vol. 28, no. 5, pp. 877-882, 2007.

[6] R. P. Chen, N. Jia, and Y. M. Chen, "Mechanism and settlement analysis of pile-supported and geogrid-reinforced embankments," Chinese Journal of Rock Mechanics and Engineering, vol. 24, no. 23, pp. 4358-4367, 2005.

[7] Y. M. Chen, W. P. Cao, and R. P. Chen, "An experimental investigation of soil arching within basal reinforced and unreinforced piled embankments," Geotext. Geomembranes, vol. 26, no. 2, pp. 164-174, 2008.

[8] R. Rui, J. Han, S. J. M. Van Eekelen, and Y. Wan, "Experimental investigation of soil-arching development in unreinforced and geosynthetic-reinforced pile-supported embankments," The Journal of Geotechnical and Geoenvironmental Engineering, vol. 145, no. 1, Article ID 4018103, 2019.

[9] G.-B. Ye, M. Wang, Z. Zhang, J. Han, and C. Xu, "Geosynthetic-reinforced pile-supported embankments with caps in a triangular pattern over soft clay," Geotextiles and Geomembranes, vol. 48, no. 1, pp. 52-61, 2020.

[10] J. Han and M. A. Gabr, "Numerical analysis of geosyntheticreinforced and pile-supported earth platforms over soft soil," Journal of Geotechnical and Geoenvironmental Engineering, vol. 128, no. 1, pp. 44-53, 2002.

[11] A. Huckert, L. Briançon, P. Villard, and P. Garcin, "Load transfer mechanisms in geotextile-reinforced embankments overlying voids: experimental and analytical approaches," Geotextiles and Geomembranes, vol. 44, no. 3, pp. 442-456, 2016.

[12] P. Villard, A. Huckert, and L. Briançon, "Load transfer mechanisms in geotextile-reinforced embankments overlying voids: numerical approach and design," Geotextiles and Geomembranes, vol. 44, no. 3, pp. 381-395, 2016.

[13] B. M. Jones, R. H. Plaut, and G. M. Filz, "Analysis of geosynthetic reinforcement inpile-supported embankments. Part I: 3D plate model," Geosynthetics International, vol. 17, no. 2, pp. 59-56, 2010.

[14] K. F. Liu, L. L. Cao, Y. Hu, and J. P. Xu, "Model test on the deformation behavior of geogrid supported by rigid-flexible piles under static load," in Proceedings of GeoShanghai 2018 International Conference: Ground Improvement and Geosynthetics. GSIC 2018, pp. 338-346, Springer, Berlin, Germany, 2018.

[15] L. Briançon and B. Simon, "Pile-supported embankment over soft soil for a high-speed line," Geosynthetics International, vol. 24, no. 3, pp. 293-305, 2017.

[16] S. N. Moghaddas Tafreshi and A. R. Dawson, "A comparison of static and cyclic loading responses of foundations on geocell-reinforced sand," Geotextiles and Geomembranes, vol. 32, pp. 55-68, 2012.

[17] S. N. M. Tafreshi and A. R. Dawson, "Behaviour of footings on reinforced sand subjected to repeated loading-comparing use of 3D and planar geotextile," Geotextiles and Geomembranes, vol. 28, no. 5, pp. 434-447, 2010.

[18] H. Xing, Z. Zhang, H. Liu, and H. Wei, "Large-scale tests of pile-supported earth platform with and without geogrid," Geotextiles and Geomembranes, vol. 42, no. 6, pp. 586-598, 2014.

[19] L. Briançon and B. Simon, "Performance of pile-supported embankment over soft soil: full-scale experiment," Journal of 
Geotechnical and Geoenvironmental Engineering, vol. 138, no. 4, pp. 551-561, 2012.

[20] J. J. Zheng, B. G. Chen, Y. E. Lu, S. W. Abusharar, and J. H. Yin, "The performance of an embankment on soft ground reinforced with geosynthetics and pile walls," Geosynthetics International, vol. 16, no. 3, pp. 173-182, 2009.

[21] P. Shen, J. Han, J. G. Zornberg et al., "Two and three-dimensional numerical analyses of geosynthetic-reinforced soil (GRS) piers," Geotextiles and Geomembranes, vol. 47, no. 3, pp. 352-368, 2019.

[22] M. J. I. Alam, C. T. Gnanendran, and S. R. Lo, "Experimental and numerical investigations of the behaviour of footing on geosynthetic reinforced fill slope under cyclic loading," Geotextiles and Geomembranes, vol. 46, no. 6, pp. 848-859, 2018.

[23] H. L. Wang and R. P. Chen, "Estimating static and dynamic stresses in geosynthetic-reinforced pile-supported track-bed under train moving loads," The Journal of Geotechnical and Geoenvironmental Engineering, vol. 145, no. 7, Article ID 04019029, 2019.

[24] G. X. Han, Q. M. Gong, and S. H. Zhou, "Soil arching in a piled embankment under dynamic load," International Journal of Geomechanics, vol. 15, no. 6, Article ID 4014094, 2015.

[25] H. V. Pham and D. Dias, “3D numerical modeling of a piled embankment under cyclic loading," International Journal of Geomechanics, vol. 19, no. 4, Article ID 4019010, 2019.

[26] H.-L. Wang, R.-P. Chen, W. Cheng, S. Qi, and Y.-J. Cui, "Fullscale model study on variations of soil stress in geosyntheticreinforced pile-supported track bed with water level change and cyclic loading," Canadian Geotechnical Journal, vol. 56, no. 1, pp. 60-68, 2019.

[27] ASTM, D2487-11 Standard Practice for Classification of Soils for Engineering Purposes (Unified Soil Classification System), ASTM International, West Conshohocken, PA, USA, 2011.

[28] Y. Chen, "Numerical simulating study on effect of low embankment expressway subgrade under the traffic load," Master's Thesis, Hohai University, Nanjing, China, 2006.

[29] J.-Q. Wang, L.-L. Zhang, J.-F. Xue, and Y. Tang, "Load-settlement response of shallow square footings on geogrid-reinforced sand under cyclic loading," Geotextiles and Geomembranes, vol. 46, no. 5, pp. 586-596, 2018.

[30] L. Luan, X. Ding, C. Zheng, G. P. Kouretzis, and Q. Wu, "Dynamic response of pile groups subjected to horizontal loads," Canadian Geotechnical Journal, vol. 57, no. 4, 2020.

[31] B. Le Hello and P. Villard, "Embankments reinforced by piles and geosynthetics-numerical and experimental studies dealing with the transfer of load on the soil embankment," Engineering Geology, vol. 106, no. 1-2, pp. 78-91, 2009.

[32] J. J. Zheng, B. G. Chen, Y. E. Lu, S. W. Abusharar, and J. H. Yin, "The performance of an embankment on soft ground reinforced with geosynthetics and pile walls," Geosynthetics International, vol. 16, no. 3, pp. 173-182, 2009. 